\title{
Clinical trials with retinoids for breast cancer chemoprevention
}

\author{
S Zanardi ${ }^{1}, D$ Serrano ${ }^{2}$, A Argusti $^{1}, M$ Barile $^{2}$, M Puntoni $^{1,3}$ and A Decensi ${ }^{1,2}$
}

\author{
${ }^{1}$ Department of Medical and Preventive Oncology, E.O. Ospedali Galliera, Mura delle Cappuccine 14, 16128, Genova, Italy \\ ${ }^{2}$ Division of Chemoprevention, European Institute of Oncology, 20141, Milano, Italy \\ ${ }^{3}$ Department of Health Sciences (DI.S.SAL.), University of Genova, 16132, Genova, Italy
}

(Requests for offprints should be addressed to A Decensi; Email: andrea.decensi@galliera.it)

\begin{abstract}
Retinoids have been studied as chemopreventive agents in clinical trials due to their established role in regulating cell growth, differentiation and apoptosis in preclinical models. Experimental evidence suggests that retinoids affect gene expression both directly, by activating and/or repressing specific genes, and indirectly, by interfering with different signal transduction pathways. Induction of apoptosis is a unique feature of fenretinide, the most widely studied retinoid in clinical trials on breast cancer chemoprevention due to its selective accumulation in breast tissue and to its favourable toxicological profile. In a phase III breast cancer prevention trial, fenretinide showed a durable trend to a reduction of second breast malignancies in premenopausal women. This pattern was associated with a favourable modulation of circulating IGF-I and its main binding protein (IGFbinding protein-3, IGFBP-3), which have been associated with breast cancer risk in premenopausal women in different prospective studies. In a subsequent biomarker study on premenopausal women who had participated in the phase III trial, high IGF-I and low IGFBP-3 baseline levels were found to predict second breast cancer risk, although the magnitude of their changes during treatment did not fulfil the requirements for suitable surrogate end-point biomarkers. In postmenopausal women, fenretinide did not reduce second breast cancer incidence, nor did it induce significant modulation of the IGF system. Similarly, fenretinide was not found to affect risk biomarkers significantly in early postmenopausal women on hormone replacement therapy, who are at increased risk of developing breast cancer. Biomarker studies of fenretinide alone or in combination with different nuclear receptor ligands are being conducted. In particular, clinical trials of fenretinide and tamoxifen have proved to be feasible, and this combination appears to be safe and well tolerated in high-risk women, especially when low-dose tamoxifen is employed. Novel retinoid $\mathrm{X}$ receptor-selective retinoids, or rexinoids, have been shown to suppress the development of breast cancer in several animal models with minimal toxicity, and are being intensively studied either alone or in combination with selective oestrogen receptor modulators, both in vitro and in vivo. The rexinoid, bexarotene, has recently been approved for the treatment of patients with cutaneous T-cell lymphoma, and a biomarker trial with bexarotene in women with high breast cancer risk is currently underway.
\end{abstract}

Endocrine-Related Cancer (2006) 13 51-68

\section{Introduction}

Despite recent progress in treatment and therapeutic strategies, breast cancer incidence, morbidity and mortality remain a major problem in Western countries. Recent trials with selective oestrogen receptor modulators (SERMs), such as tamoxifen and raloxifene, have demonstrated the principle that chemoprevention, i.e. the administration of natural or synthetic agents to reverse or suppress carcinogenesis, can reduce the incidence of breast malignancies (Cuzick et al. 2003). However, there is still a need to develop different agents to minimize toxicity as well as to prevent the appearance of ER-negative tumours.

Due to their role in the regulation of cell growth and differentiation in preclinical models, retinoids are being extensively evaluated in clinical trials of cancer prevention (Lippman et al. 1998) and the results of these trials are reviewed in the present paper. 
Retinoids, the natural and synthetic derivatives of vitamin A, are known to play a crucial role in cellular and tissue differentiation. Retinoids can suppress tumour promotion and modify some properties of fully transformed malignant cells by activating and/or repressing specific genes (Chambon 1996). In addition to the nuclear receptors and retinoic acid-responding elements (RAREs), specific cellular retinoid-binding proteins (CRBPs) bind retinoids with high affinity and regulate their metabolism, although their role in retinoid signalling remains unclear (Spinella \& Dmitrovsky 2000).

Retinoid receptors are expressed in normal and malignant epithelial breast cells and are critical for normal development. Although the mechanism underlying breast cell growth inhibition by retinoids has not yet been completely elucidated, experimental evidence suggests that it is likely to involve multiple signal transduction pathways and to result from direct and indirect effects on gene expression. Binding of retinoids to the nuclear receptors (i.e. retinoic acid receptor (RAR)- $\alpha,-\beta$ and $-\gamma$ and retinoid $X$ receptor (RXR)- $\alpha$, $-\beta$ and $-\gamma$ ), which are ligand-activated transcription factors, leads to regulation of several cellular processes, including growth, differentiation and apoptosis (Simeone \& Tari 2004). Several retinoids are able to inhibit the activator protein-1 (AP-1) transcription pathway, which is activated upon growth factor signalling (Fanjul et al. 1994, Li et al. 1996, Shah et al. 2002) and is involved in breast cancer cell proliferation and transformation (Chen et al. 1996). In addition, growth inhibition of breast cancer cells by retinoic acid has been associated with induction of the expression of RAR- $\beta$, which may act as a tumour suppressor and appears to be down-regulated in breast cancer tissue and cell lines and, conversely, upregulated in normal mammary epithelial cells (Zhang et al. 1996).

\section{The synthetic retinoid fenretinide}

The retinoid most widely studied in chemoprevention clinical trials is the synthetic amide of retinoic acid $N$-(4-hydroxyphenyl)retinamide (4-HPR), or fenretinide. Fenretinide was synthesized in the late 1960s, and its biological activity assayed by Sporn and co-workers, who also showed the preferential accumulation of this drug in the breast rather than in the liver (Sporn et al. 1976). The inhibition of the development of chemically induced mammary carcinoma in rats by fenretinide was first described by in 1979 (Moon et al. 1979). Since then, in the light of promising data in different experimental models and of a favourable toxicity profile as compared with other retinoids, fenretinide has been studied in chemoprevention trials targeting different organs (Kelloff et al. 1994).

Fenretinide has been found to exert significant chemopreventive activity in a large variety of in vitro and in vivo systems. Although its mechanism of action is not yet completely clarified, it may act through different mechanisms compared with other retinoids. Fenretinide effectively inhibits the proliferation of breast cancer cells that do not express RARs and, actually, has a very poor affinity to this receptor class (Sheikh et al. 1995). Current experimental data suggest that fenretinide induces inhibitory effects by both receptor-dependent and -independent mechanisms (Sheikh et al. 1995, Fanjul et al. 1996, Sun et al. 1999). These mechanisms include both an increase in the expression of RAR- $\beta$ and a decrease in the expression of cell cycle modulators, such as cyclin D and cyclin-dependent kinases, in different cancer cell lines, including breast cancer cells (Liu et al. 1998, Sabichi et al. 1998, Panigone et al. 2000).

A unique feature of fenretinide is its ability to inhibit cell growth through the induction of apoptosis rather than differentiation, an effect that is strikingly different from that of the parental compound all-trans retinoic acid (Lotan 1995, Wu et al. 2001). The mechanisms underlying the apoptotic effect of fenretinide are not yet well defined, but it has recently become evident that 4-HPR-mediated apoptosis is tissue specific and that multiple mechanisms may operate within specific tissues (Simeone \& Tari 2004). Both elevations in the levels of the sphingolipid ceramide (Maurer et al. 2000) and the production of nitric oxide (NO) by nitric oxide synthases (NOS) (Simeone et al. 2002, 2003) have been implicated in fenretinide-mediated apoptosis in breast cancer cells. A mechanism specific to fenretinide as compared with other retinoids is the generation of reactive oxygen species (ROS), such as hydrogen peroxide and superoxide, which seem to be critical in mediating apoptosis in different cancer cell types (Delia et al. 1997, Oridate et al. 1997, Tosetti et al. 2003). These mechanisms may be interrelated and in breast cancer cells it has been shown that NO-mediated induction of apoptosis requires mitochondrial damage, including cytochrome $\mathrm{C}$ release, disruption of mitochondrial transmembrane potential and ROS generation, as well as activation of caspases (Umanski et al. 2000).

Additional mechanisms, which may be relevant for both the therapeutic and the preventive use of fenretinide, are currently under investigation. For example, fenretinide was shown to decrease the activity of telomerase, a biomarker of breast cancer development 
and progression, in N-methyl-N-nitrosourea (MNU)induced mammary tumours as well as in the bronchial epithelium of cigarette smokers (Bednarek et al. 1999, Bowman et al. 2002). It has also been suggested that retinoids inhibit cell growth by reducing the expression of growth-stimulating factors or by inducing the expression of growth-inhibitory factors. In vitro, breast cancer cell growth inhibition by fenretinide or retinoic acid correlated with either decreased secretion of insulin-like growth factor-I (IGF-I), a potent stimulator of epithelial cell growth, or increased secretion of IGF-binding proteins (IGFBPs) (Favoni et al. 1998, Fontana et al. 1991). In addition, fenretinide-induced apoptosis is inhibited by blocking transforming growth factor- $\beta$ (TGF- $\beta$ ) activity with neutralizing antibodies, and breast cancer cells defective in TGF- $\beta 1$ signalling are resistant to apoptosis induced by fenretinide (Herbert et al. 1999). However, it remains to be determined whether alterations in growth factor signalling represent a mechanism of retinoid action or merely a marker of activity.

The expression of HER-2/neu reduces the ability of fenretinide to induce apoptosis in breast cancer cells. One of the mechanisms involved is a decrease in NO production mediated by NOS, resulting from induction of cyclooxygenase-2 (COX-2) expression by HER-2/neu through activation of Akt (Simeone et al. 2003, 2004). Interestingly, however, fenretinide has been found to down-regulate c-erbB-2 protein and mRNA in overexpressing breast cancer cell lines and to induce apoptosis also in HER-2/neu-transformed cells (Rao et al. 1998, Jinno et al. 1999), a phenotype which is known to be tamoxifen resistant. Finally, it has recently been shown that fenretinide is able to induce NO-mediated apoptosis in BRCA-1-mutated breast cancer cells (Simeone et al. 2005).

\section{Fenretinide for breast cancer prevention}

Both fenretinide and its major metabolite 4-methoxyphenylretinamide (4-MPR) selectively accumulate in the human breast (Mehta et al. 1991), rendering this agent an attractive candidate for breast cancer chemoprevention.

Women with early breast cancer have a risk of contralateral cancer of approximately $8 / 1000$ per year, which corresponds to 5-6 times the risk in the general population in the same age range (Broet et al. 1995). In the 1980s these women were not candidates for adjuvant systemic therapy, and therefore represented a suitable population to test the efficacy of fenretinide for prevention of a second breast cancer.

A phase I dose ranging study was completed, and a $200 \mathrm{mg}$ daily dose was selected as the safest one (Costa et al. 1989). This study also provided important information on the pharmacokinetics of fenretinide (Formelli et al. 1989). Fenretinide administration induced a dose-related linear decrease of plasma retinol, which was associated with diminished dark adaptation (Formelli et al. 1989). In order to minimize this side effect, a 3-day treatment interruption at the end of each month was introduced to increase plasma retinol concentrations, thus allowing the partial recovery of retinal storage. Studies of the mechanisms responsible for retinol reduction have indicated that fenretinide has a high binding affinity to retinolbinding protein (RBP), thus interfering with the RBP-retinol-transthyretin complex formation and the secretion of retinol from the liver (Berni \& Formelli 1992). Additional mechanisms, including a specific effect of fenretinide on ocular turnover of vitamin A, have been advocated to explain the dark adaptation impairment associated with the administration of this retinoid (Lewis et al. 1996).

Daily chronic administration of $200 \mathrm{mg}$ fenretinide for 5 years resulted in an average plasma concentration of $350 \mathrm{ng} / \mathrm{ml}$ (i.e. approximately $1 \mu \mathrm{M}$ ), which remained constant throughout the 5-year treatment period (Formelli et al. 1993). Concentrations of 4-MPR were similar to those of the parental drug. Retinol concentrations were reduced by $65 \%$ on average, and this reduction was constant during the 5 -year treatment period. Plasma 4-HPR concentrations were at the limits of detection at 6 and 12 months after drug discontinuation, whereas the concentrations of 4-MPR were approximately 5 times higher. Baseline retinol concentrations recovered after 1 month (Formelli et al. 1993).

\section{The phase III prevention trial of fenretinide}

A multicentre phase III randomized trial, coordinated by the Istituto Nazionale dei Tumouri in Milan, started in 1987 (Veronesi et al. 1999). Eligible patients were stage I breast cancer patients, aged 33-70 years, who had been operated on for breast cancer within the previous 10 years and who had received no systemic adjuvant therapy. Women were randomly assigned to receive either no treatment or fenretinide given orally at a daily dose of $200 \mathrm{mg}$ for 5 years. A placebo control arm was not included in the study design because of both the large capsule size and the objective nature of the main outcome measure. A 3-day drug interval at the end of each month was recommended, in order to allow retinol recovery and to minimize dark adaptation impairment. 
The main outcome measure was the occurrence of contralateral breast cancer as the first malignant event. The secondary end-point was the incidence of ipsilateral breast cancer reappearance, defined as either local recurrence in the same quadrant or occurrence of a second breast malignancy in a different quadrant from the primary tumour. The use of this end-point was considered appropriate for a preventive intervention because it is, at least in part, due to the progression of premalignant or early-malignant cells. The occurrence of distant metastases (including regional relapse) and death were recorded, but they were not considered efficacy end-points as fenretinide was not thought to be active in the late phases of breast carcinogenesis. The study was powered at $90 \%$ with a $5 \%$ type I error probability level (for a two-sided test) to detect a $50 \%$ reduction in the incidence of contralateral breast cancer, assuming an annual rate of 8/1000 in the control arm and a 3-year linear lag to obtain a full intervention effect. A $10 \%$ drop-out rate was anticipated (De Palo et al. 1997).

Accrual started on March 1987 and was closed on July 1993, below the expected sample size of 3500 , because a National Cancer Institute alert recommended the administration of adjuvant systemic treatment for node-negative breast cancer patients. A total of 2972 patients entered the study, 2867 of whom were assessable, giving an $87 \%$ power to detect the expected difference. The two groups were well balanced for all patient and tumour characteristics.

The results after a median follow-up duration of 97 months have been reported in detail (Veronesi et al. 1999). Fenretinide showed no effect on contralateral breast cancer occurrence and a non-significant $17 \%$ reduction in ipsilateral breast tumour reappearance. However, a different trend was noted when the analysis was stratified by menopausal status; there was a beneficial trend in premenopausal women on both contralateral and ipsilateral breast cancer (hazard ratio (HR) 0.66 , 95\% confidence interval (CI) 0.41-1.07; and HR 0.65 , 95\% CI 0.46-0.92 respectively) and an opposite trend in postmenopausal women (contralateral breast cancer HR 1.32, 95\% CI $0.82-2.15$; ipsilateral breast cancer HR $1.19,95 \%$ CI $0.75-1.89$ ). No effect of fenretinide treatment was observed on distant metastases and death, either overall or in the two subgroups separately. The frequency of second primary tumours was comparable in the two groups (38 in the fenretinide arm versus 40 in the control arm), with no significant excess of a specific tumour in either treatment arm.

Interestingly, the incidence of ovarian cancer during the 5-year intervention period was significantly lower in the fenretinide arm (no cases versus six cases in the control group), whereas three cases of ovarian cancer occurred in the fenretinide group after treatment discontinuation (De Palo et al. 1995). An update of the effect of fenretinide on ovarian cancer has recently been provided (De Palo et al. 2002). After a median of 121 months, a total of six cases of ovarian cancer had occurred in the fenretinide arm as opposed to ten cases in the control arm $(P=$ n.s. $)$. A protective effect was suggested in women with a high probability of carrying a BRCA-1 mutation. Further clinical trials are necessary to clarify this potentially important clinical effect of fenretinide (Veronesi \& Decensi 2001).

The findings of the phase III trial support the role of fenretinide as a preventive agent acting at different steps of breast carcinogenesis, but indicate its lack of efficacy on the progression to a more malignant phenotype, possibly as a result of the loss of retinoid receptor expression (Widschwendter et al. 1997). This study seems to suggest a beneficial effect of fenretinide in reducing second breast cancer risk in premenopausal women. Since the analysis of the interaction between intervention and menopausal status was not initially planned, these results are hypothesis generating and should be confirmed in additional studies. However, recent findings indicate that the favourable trend on contralateral breast cancer and ipsilateral breast reappearance in premenopausal women appears to be durable up to 15 years of follow-up (U Veronesi et al., unpublished observations), providing the rationale for a phase III primary prevention trial in young women at high risk for breast cancer.

\section{Fenretinide and the IGF system}

The search for an interaction between fenretinide and age or menopausal status on second breast malignancy was prompted by a previous observation of the different effect of fenretinide on plasma IGF-I according to age or menopausal status in a subset of 60 subjects participating in the phase III trial (Torrisi et al. 1993). In this study, a reduction of circulating IGF-I was observed after administration of fenretinide for 12 months in premenopausal women, whereas no significant change was observed in postmenopausal women $(P<0.05$ for the interaction between age and treatment). A slight, but significant, up-regulation of serum IGFBP-3 was associated with the IGF-I decline (Torrisi et al. 1998). Consistently, fenretinide has been shown to down-regulate the IGF system and to inhibit IGF-I-stimulated growth in both ER-positive and ER-negative breast cancer cell lines (Favoni et al. 1998). 
IGF-I is a key regulator of proliferation and apoptosis in normal and malignant cells, including breast cancer cells (Pollak 2000). Approximately 80\% of circulating IGFs are bound to IGFBP-3, which affects cell growth by regulating IGF bioavailability and IGF-I receptor responsiveness to IGF-I ( $\mathrm{Yu} \&$ Rohan 2000, Moschos \& Mantzoros 2002). In addition to modulating IGF-I and -II, IGFBP-3 also exerts intrinsic inhibitory effects on breast cancer cell growth and survival that are independent of IGF-I (Gill et al. 1997, Rajah et al. 1997). A positive association between higher plasma IGF-I levels and/or lower levels of IGFBP-3, and risk of breast, prostate, colorectal and lung cancers has been reported in large prospective studies in healthy people (Chan et al. 1998, Hankinson et al. 1998, Ma et al. 1999, Giovannucci et al. 2000, London et al. 2002). In particular, an association between high circulating levels of IGF-I and increased risk of breast cancer was found in premenopausal but not postmenopausal women (Hankinson et al. 1998, Toniolo et al. 2000). This association has been confirmed in a recent large metaanalysis (Renehan et al. 2004), consistent with the notion that IGF-I interacts with the oestrogen signal to increase cell proliferation (Clarke et al. 1997, Lai et al. 2001). These findings suggest that lowering IGF-I availability may contribute to the reduction of breast cancer risk in premenopausal women.

In a subsequent study (Decensi et al. 2001), the circulating levels of IGF-I, IGFBP-3 and their molar ratio were measured at yearly intervals for up to 5 years in 60 subjects aged $\leq 50$ years and 60 subjects aged $>50$ years allocated to either fenretinide or no treatment within the phase III study (Veronesi et al. 1999). In women aged $\leq 50$ years, measurements of IGF-II, IGFBP-1 and IGFBP-2 were also performed. The associations between IGFs and drug or metabolite plasma concentrations were also investigated. All IGFs were relatively stable over 5 years in the control group. Compared with controls and after adjustment for baseline, treatment with fenretinide for 1 year induced a decrease of IGF-I levels and of the IGF-I : IGFBP-3 molar ratio. The following changes were observed: IGF-I, $-13 \%(95 \% \mathrm{CI},-25$ to $1 \%)$ in women aged $>50$ years and $-3 \%(95 \% \mathrm{CI},-16$ to $13 \%)$ in women aged $>50$ years; IGFBP-3, $-4 \%(95 \% \mathrm{CI}$, -12 to $6 \%$ ) in both age groups; IGF-I: IGFBP-3 molar ratio, $-11 \%(95 \% \mathrm{CI},-22$ to $1 \%)$ in women aged $>50$ and $1 \%(95 \% \mathrm{CI},-11$ to $16 \%)$ in women aged $>50$ years. These effects were apparently maintained for up to 5 years. No change in other IGFs was noted. Drug and metabolite concentrations were negatively correlated with IGF-I and IGF-I : IGFBP-3 molar ratio in women aged $\leq 50$ years. It was concluded that fenretinide induces a moderate decline of IGF-I levels in women aged $\leq 50$ years, and the study of the association between IGF-I change and the reduction of second breast cancer in premenopausal women warrants further study.

\section{Relationships between plasma IGF-I and IGFBP-3 and second breast cancer risk with fenretinide treatment}

In contrast to healthy women, no data are available on the association of IGF-I and IGFBP-3 with the risk of second breast malignancy in women with a diagnosis of breast cancer. Moreover, it is unknown whether a reduction in IGF-I levels during preventive intervention may predict the clinical effect of fenretinide, thus representing a potentially useful surrogate end-point biomarker.

To answer these questions, a study was conducted at the European Institute of Oncology, Milan (Decensi et al. 2003), on a large group of patients who had participated in the phase III trial with fenretinide (Veronesi et al. 1999). The objective was to determine whether circulating IGF-I and IGFBP-3 levels predict the risk of second breast malignancy in women aged $\leq 50$ years and whether any changes during fenretinide treatment explain the reduction in second breast malignancy observed in the phase III trial.

Among the patients enrolled in the trial, 302 women on fenretinide and 220 controls who were $<50$ years old at randomization and provided plasma samples both at baseline (pretreatment) and during a 9.4-year follow-up period were considered eligible for this study. The study outcome was the occurrence of a second breast malignancy, defined as either ipsilateral breast tumour reappearance or contralateral breast cancer as first event. The two types of event were pooled in order to increase the statistical power of the study, using an approach previously described by others (Fisher et al. 1999).

Second breast cancer risk was reduced by $39 \%$ (HR, $0.61 ; 95 \% \mathrm{CI}, 0.40-0.94 ; P=0.026)$ in the fenretinide group.

The prognostic effects of baseline IGF-I, IGFBP-3 and their ratio were investigated by fitting Cox models in the control group only, in order to avoid the interference of fenretinide treatment. In this group, high IGF-I and, particularly, low IGFBP-3 levels were associated with elevated second breast cancer risk (top versus bottom tertile, IGF-I : HR 1.94, 95\% CI 0.87-4.31, $P=0.105$; IGFBP-3: HR 0.40, 95\% CI 0.18-0.93, $P=0.033$ ). 
Fenretinide treatment reduced circulating IGF-I, IGFBP-3 and the IGF-I : IGFBP-3 ratio by $8 \%(95 \%$ CI, $2-12 \% ; P=0.004), 3 \%$ (95\% CI, $1-5 \% ; P=0.002)$ and $5 \%(95 \% \mathrm{CI}, 0-10 \% ; P=0.050)$ respectively. The analysis of IGF-1 and the IGF-1:IGFBP-3 ratio as surrogate end-point biomarkers was performed according to the approach used by Li et al. (2001), by fitting a Cox model containing as covariates the marker itself, expressed as the ratio between the individual follow-up measurements and its baseline value, and treatment. An ideal surrogate explains all of the treatment effect, although surrogates explaining at least $50 \%$ of treatment effect can be considered adequate for practical purposes (Freedman et al. 1992). However, the percentage of treatment effect explained by IGF-I and IGF-I : IGFBP-3 reductions was only $4.8 \%(95 \% \mathrm{CI}, 0.8-28.9 \%)$ and $3.1 \%(95 \%$ CI, 0.5-20.8\%) respectively.

It was concluded that fenretinide induces a moderate decrease of IGF-I levels, which marginally explains second breast cancer risk reductions observed in women aged $\leq 50$ years. In fact, the reduction of IGF-1 explained only $4.8 \%$ of the clinical effect of fenretinide, a level about 10 -fold lower than the $50 \%$ threshold of clinical relevance (Freedman et al. 1992). This observation suggests that the inhibition of circulating IGF-I bioactivity does not represent a major pathway of the preventive effect of fenretinide in this subset of women. Importantly, it was shown in this study that high IGF-I and, particularly, low IGFBP-3 levels predicted second breast cancer risk in this age group (Decensi et al. 2003).

\section{Safety and tolerability of fenretinide}

The Milan trial, with a 5-year administration of fenretinide, provided a vast corpus of information on the long-term safety and tolerability of this retinoid, although an accurate evaluation of toxicity was hampered by the lack of a placebo control group. Dermatological, gastrointestinal, visual and ophthalmological events were relatively frequent, but mostly of mild extent (G1 according to the World Health Organization Toxicity Criteria).

In a detailed analysis of the phase III trial (Camerini et al. 2001), the most common adverse events were diminished dark adaptation (cumulative incidence, $19 \%)$ and dermatological disorders (18.6\%) - such as skin and mucosal dryness, pruritus and urticaria. Less common events were gastrointestinal symptoms $(13 \%)$ and alterations of the ocular surface $(10.9 \%)$. Women in the control group complained of diminished dark adaptation, dermatological disorders, gastrointestinal symptoms and alterations of the ocular surface in $2.9,2.9,5.4$ and $3.2 \%$ of cases respectively. Interestingly, most side effects decreased with time and were significantly more frequent in postmenopausal women. However, only 63 of 1432 women $(4.4 \%)$ discontinued treatment for drug-related toxicity, and no life-threatening events were observed. Objective assessment of laboratory tests did not show any difference between the two arms in terms of number of subjects with altered findings. Importantly, in contrast with other retinoids, prolonged administration of fenretinide was not found to be associated with significant alterations of bone mineral density of the forearm in a study that addressed this issue (Decensi et al. 1999). However, a trend towards an increase in bone reabsorption markers was observed in this study, suggesting the need for further assessment at different skeletal sites.

An objective evaluation of fenretinide-induced dark adaptation impairment was performed in a subset of women who had been on treatment for a median of 32 months (Decensi et al. 1994), using the GoldmannWeekers adaptometer test. This test allows the detection of subclinical vitamin A deficiency through a sensitive and reliable measurement of alterations in dark adaptability, such as nyctalopia (diminished dark adaptation). Results of the Goldmann-Weekers adaptometer test were compared with plasma retinol levels and with the results of a subjective evaluation through a structured questionnaire. Mild and moderate alterations of dark adaptability, i.e. a prolongation of the time to the cone-rod break and a higher final rod threshold, were observed in 23.5 and $26.5 \%$ of women respectively, and were associated with plasma retinol levels below 160 and $100 \mathrm{ng} / \mathrm{ml}$ respectively. Importantly, only half of the patients with positive dark adaptometry were symptomatic, thus raising the issue of the real-life implications of fenretinide-associated visual alterations. Similar data were reported after a shorter duration of fenretinide administration in another study, where a low rate of complaints for reduced dark adaptability was noted in patients with alterations of the Goldmann-Weekers test (Caruso et al. 1998). Older and heavier women showed the highest fenretinide-induced retinol decrease (Torrisi et al. 1994) and, therefore, were at a higher risk of developing visual symptoms.

\section{Fenretinide and tamoxifen trials}

It is well known that, in the therapeutic setting, polychemotherapy with combinations of drugs is superior to monochemotherapy. Similarly, the concept 
of combining agents with different mechanisms of action in an attempt to increase efficacy on complementary molecular targets while minimizing side effects is increasingly being pursued in chemoprevention of breast cancer. In preclinical models, the combined administration of fenretinide and tamoxifen has proven to be additive or synergistic in both the growth inhibition of MCF-7 cells (Fontana 1987) and the prevention of MNU-induced mammary carcinomas (Ratko et al. 1989). Moreover, the preventive activity of 9-cis-retinoic acid against MNU-induced mammary tumours in Sprague-Dawley rats is enhanced by combination with fenretinide (Cope et al. 2004) and with either tamoxifen or raloxifene (Anzano et al. 1994, 1996).

The safety and the tolerability of the combination of fenretinide and tamoxifen has been investigated in breast cancer clinical trials both in metastatic patients (Zujewski et al. 1999) and in the adjuvant setting (Cobleigh et al. 2000), as well as in healthy women at increased risk (Conley et al. 2000).

In a pilot trial by Zujewski et al. (1999) the combination of fenretinide (at a $400 \mathrm{mg}$ daily dose for 25 out of 28 days) and tamoxifen (at a $20 \mathrm{mg}$ daily dose) was evaluated in metastatic breast cancer patients who had previously been treated with tamoxifen or who had hormone receptor negative disease. No objective tumour responses were observed in 24 out of 31 evaluable patients. Five patients $(16 \%)$ discontinued treatment due to toxicity, and symptomatic nyctalopia developed in one-third of treated patients. It was concluded that the $400 \mathrm{mg}$ dose of fenretinide is unsuitable for use in prevention studies, and that the combination is not active in this subset of patients with advanced disease.

Additional concerns regarding the feasibility of this combination have been raised by the high dropout rate $(30 \%)$ observed in a trial of fenretinide $(400 \mathrm{mg} /$ day $)$ and tamoxifen, versus placebo and tamoxifen, as an adjuvant treatment in elderly patients with breast cancer (Cobleigh et al. 2000). In that study, a higher incidence of grade I-II leukopaenia, hypercalcaemia, nyctalopia, and pulmonary and genitourinary side effects was noted in the combination arm. Interestingly, women on fenretinide and tamoxifen experienced a borderline significant reduction in hot flashes compared with women on tamoxifen and placebo. While the explanation for this observation is unclear, one possible interpretation suggests that fenretinide might act as a weak oestrogenic compound at the hypothalamic level.

In another pilot study involving 32 healthy at-risk women, fenretinide was administered for four cycles at a daily oral dose of $200 \mathrm{mg}$ for 25 out of 28 days (Conley et al. 2000). Tamoxifen was started after the first month of fenretinide administration, at a daily dose of $20 \mathrm{mg}$, and continued for 24 months. This schedule allowed the investigation of the pharmacodynamics and the toxicity of 4-HPR as single agent as well as after tamoxifen administration. No interference of tamoxifen on retinoid plasma concentrations was observed. The incidence of fenretinide-induced nyctalopia was $6 \%$ only, and reversed completely after fenretinide discontinuation. Four subjects stopped treatment due to side effects, and hot flushes were reported in $84 \%$ of women after the start of tamoxifen.

In another trial evaluating surrogate end-point biomarkers for the combination of fenretinide and tamoxifen, women with ductal carcinoma in situ (DCIS) or early invasive breast cancer were randomized to either placebo or the combination of fenretinide and tamoxifen for a median of 19 days between initial core biopsy and definitive surgery (Singletary et al. 2002). A total of 52 subjects were registered, and 36 were assessable for analysis. The main outcome measure was the change induced by the combination on $\mathrm{Ki}-67$ expression at the tumour level. No difference was noted between the two arms, but there was a trend toward a higher response in ER-positive versus ER-negative patients. However, the limited sample size prevented reliable statistical conclusions to be drawn.

A clinical trial with the combination of fenretinide and tamoxifen was recently conducted at the European Institute of Oncology. The primary objective of the trial was to assess the possible interaction between lowdose tamoxifen and fenretinide on a set of surrogate end-point biomarkers in premenopausal women at increased risk of developing breast cancer. The primary end-points were the changes in circulating IGF-I and mammographic percentage density after 24 months of intervention. Additional end-points included changes in endometrial thickness and proliferation, changes in size and sonographic characteristics of the ovaries (such as presence and volume of ovarian cysts), presence of atypia in fine-needle aspirates and, finally, adverse events. Premenopausal women with a history of intraepithelial neoplasia or minimally invasive breast cancer, and healthy women at high risk according to the Gail model were eligible for this trial. The study was a randomized, doubleblind, placebo-controlled, phase IIb trial with a $2 \times 2$ factorial design. Subjects were randomized to either fenretinide $(200 \mathrm{mg} /$ day $)$, or tamoxifen $(5 \mathrm{mg}$ /day), or both agents, or placebo for 2 years (Fig. 1). 


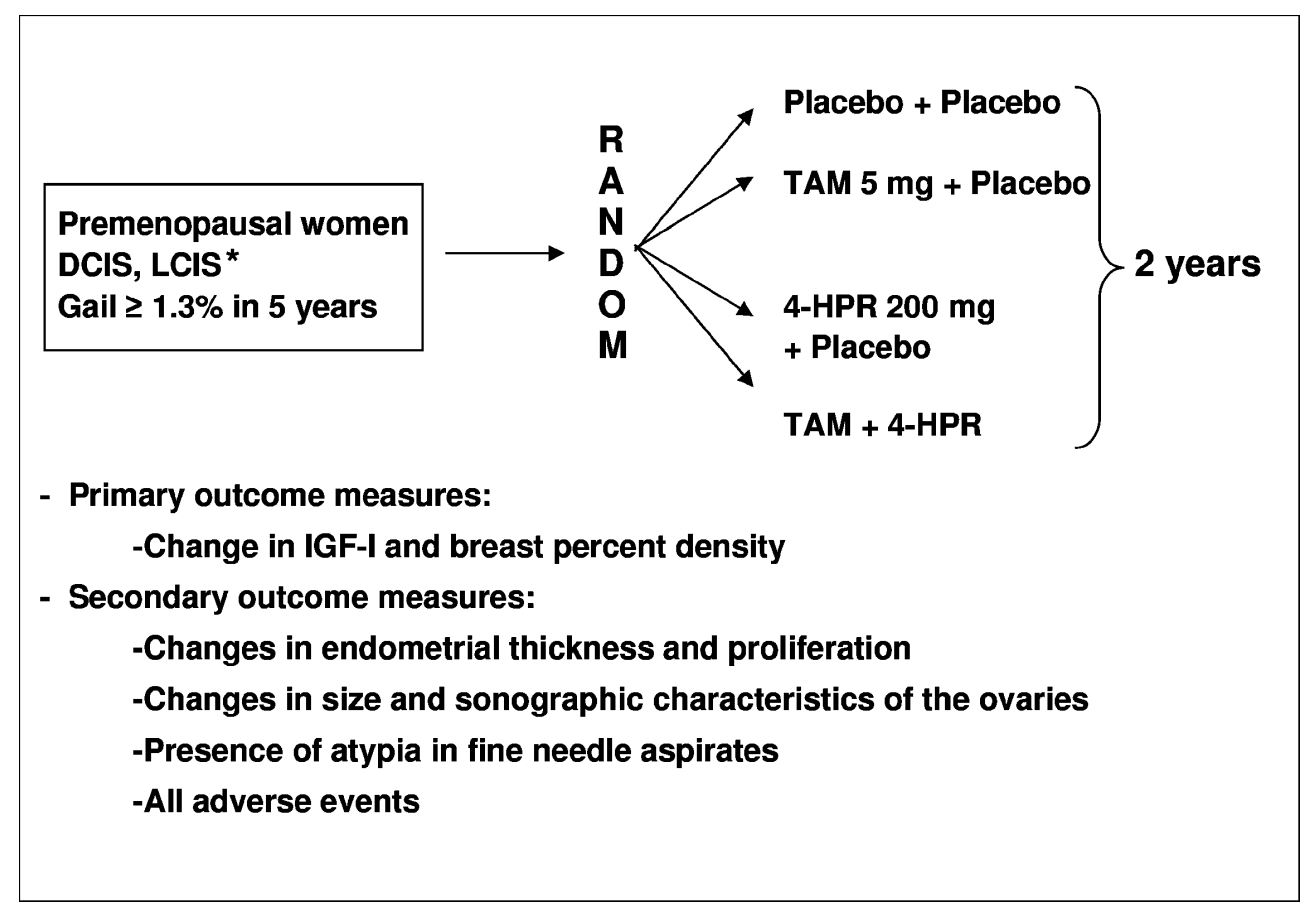

Figure 1 Study design of the low-dose tamoxifen and fenretinide trial. DCIS, ductal carcinoma in situ; LCIS, lobular carcinoma in situ; TAM, tamoxifen; 4-HPR, fenretinide.

Accrual was stopped on 19 April 2002, based on the lack of an interaction between the two agents on the primary end-points. Treatment and study procedures continued, however, given the absence of toxicity concerns. At the time of the last analysis (Decensi et al. 2004a), 235 subjects had been randomized, of whom 40 were still on treatment, 35 had dropped out of the study due to refusal (19 subjects) or adverse events (16 subjects), and 160 had completed the 2-year treatment intervention. A $15 \%$ reduction of circulating IGF-I was observed in subjects treated with tamoxifen, versus a $2 \%$ reduction in the fenretinide treatment group; no evidence of interaction between the two drugs on IGF-I levels was apparent. Importantly, at the low dose employed, tamoxifen did not induce any excess of gynaecological disorders, including endometrial polyps and ovarian cysts, nor was it associated with an increase in endometrial thickness in premenopausal women. Such an increase, however, was observed in women in the tamoxifen arm who became menopausal during the study. Interestingly, no changes in endometrial thickness were observed in subjects who became menopausal during treatment with the combination. The most frequent side effects observed during treatment are summarized in Table 1 . There was no significant difference in any adverse event among the four arms. Of the two serious adverse events, one stage I endometrial cancer occurred in the fenretinide arm and one optic nerve ischaemia in the tamoxifen arm. So far, 24 primary or recurrent breast cancers have been observed, with no difference among arms. Although mature results are awaited, the combination of fenretinide and low-dose tamoxifen proved to be safe and well tolerated.

\section{Effect of fenretinide in hormone replacement therapy (HRT) users}

HRT relieves climateric symptoms, but is associated with an increased risk of breast cancer, particularly when combined oestrogen-progestin HRT is employed (Collaborative Group on Hormonal Factors in Breast Cancer 1997). Such an increased risk has been confirmed in the Women's Health Initiative (WHI) trial on the use of oral conjugated equine oestrogen (CEE) and medroxyprogesterone acetate (MPA), where an excess risk for both breast cancer and cardiovascular disease (CVD) events was observed in the HRT arm as compared with placebo (Writing Group for the Women's Health Initiative Investigators 2002). 
Endocrine-Related Cancer (2006) 13 51-68

Table 1 Adverse events/reactions during treatment in the low-dose tamoxifen and fenretinide trial

\begin{tabular}{lcccc}
\hline Event/reaction & $\begin{array}{c}\text { Tamoxifen } \\
\text { placebo } \\
(\boldsymbol{n}=\mathbf{5 8 )}\end{array}$ & $\begin{array}{c}\text { Fenretinide }+ \\
\text { placebo } \\
(\boldsymbol{n}=\mathbf{5 9 )}\end{array}$ & $\begin{array}{c}\text { Tamoxifen+ } \\
\text { fenretinide } \\
(\boldsymbol{n}=\mathbf{6 0})\end{array}$ & $\begin{array}{c}\text { Placebo }+ \\
\text { placebo } \\
(\boldsymbol{n}=\mathbf{5 8})\end{array}$ \\
\hline Ocular/visual & 19 & 25 & 23 & 25 \\
Dermatology/skin & 17 & 22 & 23 & 25 \\
Hot flashes & 15 & 18 & 17 & 13 \\
Vaginal dryness/discharge & 15 & 10 & 9 & 10 \\
Dysuria, incontinence & 5 & 7 & 6 & 5 \\
Vaginal bleeding & 7 & 4 & 5 & 4 \\
Endometrial polyps & 4 & 6 & 4 & 3 \\
Sweats, weight gain & 9 & 4 & 5 \\
\hline
\end{tabular}

In contrast to oral CEE, little is known of the chronic administration of transdermal 17- $\beta$ oestradiol $\left(E_{2}\right)$. The Million Women Study has recently shown that, compared with never users, women on oestrogen replacement therapy (ERT) with transdermal $\mathrm{E}_{2}$ have a similar breast cancer risk as women taking oral CEE (Beral \& Million Women Study Collaborators 2003), although transdermal $\mathrm{E}_{2}$ does not seem to be associated with increased venous thromboembolism and, consequently, might have a safer profile on CVD risk (Scarabin et al. 2003).

To provide additional insights into the effects of transdermal $E_{2}$ on breast cancer risk, the changes induced by oral CEE or transdermal $\mathrm{E}_{2}$, administered in a continuous sequential regimen with MPA, on a panel of breast cancer risk biomarkers have been compared in a study recently conducted at the European Institute of Oncology (Decensi et al. 2004b). In addition, the effect of fenretinide during ERT was also investigated in this study, in an attempt to reduce breast cancer risk in ERT users. The use of the retinoid is justified by the results of the phase III prevention trial (Veronesi et al. 1999), where fenretinide showed a favourable clinical outcome in premenopausal women but not in postmenopausal women, in line with the notion that sex hormones sensitize breast cancer cells to the retinoid-induced growth inhibition (Roman et al. 1993).

Study participants were healthy, postmenopausal, de novo ERT users with 6- to 60-month amenorrhea and follicle-stimulating hormone (FSH) levels greater than $40 \mathrm{U} / 1$. Subjects were randomized by a $2 \times 2$ factorial design to either $0.625 \mathrm{mg} /$ day oral CEE or transdermal $\mathrm{E}_{2}, 50 \mu \mathrm{g} /$ day released by a weekly patch, and to fenretinide $100 \mathrm{mg} /$ twice a day orally or placebo for 12 months (Fig. 2). Assignment to the oestrogen route was unblinded since the comparison in symptom relief was not a main study end-point. Sequential MPA, $10 \mathrm{mg} /$ day orally for the first 12 days of each month, was added to continuous oestrogen therapy in each arm. A 3-day rest period from the retinoid capsules was prescribed monthly in order to increase plasma retinol levels, thus allowing sufficient uptake for normal night vision.

The aims of the trial were: (a) to compare the effect of oral CEE and transdermal $\mathrm{E}_{2}$ at biologically comparable doses (Hillard et al. 1994); (b) to determine the effect of fenretinide on biomarkers of breast cancer risk, including the 6- and 12-month changes in circulating IGF-I (primary end-point), IGFBP-3, IGF-I : IGFBP-3 molar ratio and sex hormone binding globulin (SHBG), and the 12-month change in mammographic percentage density - as measured by a computerized method. With regard to the last two biomarkers, low circulating levels of SHBG have been found to be associated with increased breast cancer risk in a metanalysis of nine prospective studies (Key et al. 2002), and $1 \%$ increases in computerized mammographic density have been found to correspond to a $2 \%$ increase in the relative risk of breast cancer (Boyd et al. 1995). Serial measurements of plasma concentrations of retinol, fenretinide and its main metabolite, 4-MPR, were performed to assess relationships with drug activity and toxicity and to study pharmacokinetic interactions with the hormonal agents. While the study was progressing, the unexpected results of the Heart and Oestrogen/Progestin Replacement Study (Hulley et al. 1998) and the initial WHI study alert on CVD risks associated with oral CEE and MPA prompted the investigation, for safety reasons, of the 6-and 12-month changes in the levels of ultrasensitive C-reactive protein (CRP), an index of low-grade inflammation associated with CVD risk in healthy women (Ridker et al. 2000, Walsh et al. 2000).

A total of 226 women were randomized in the trial. After 12 months, oral CEE decreased IGF-I by $26 \%$ $(95 \%$ CI, $22-30 \%)$ and increased SHBG by $96 \%$ (95\% CI, 79-112\%) relative to baseline, whereas no change 


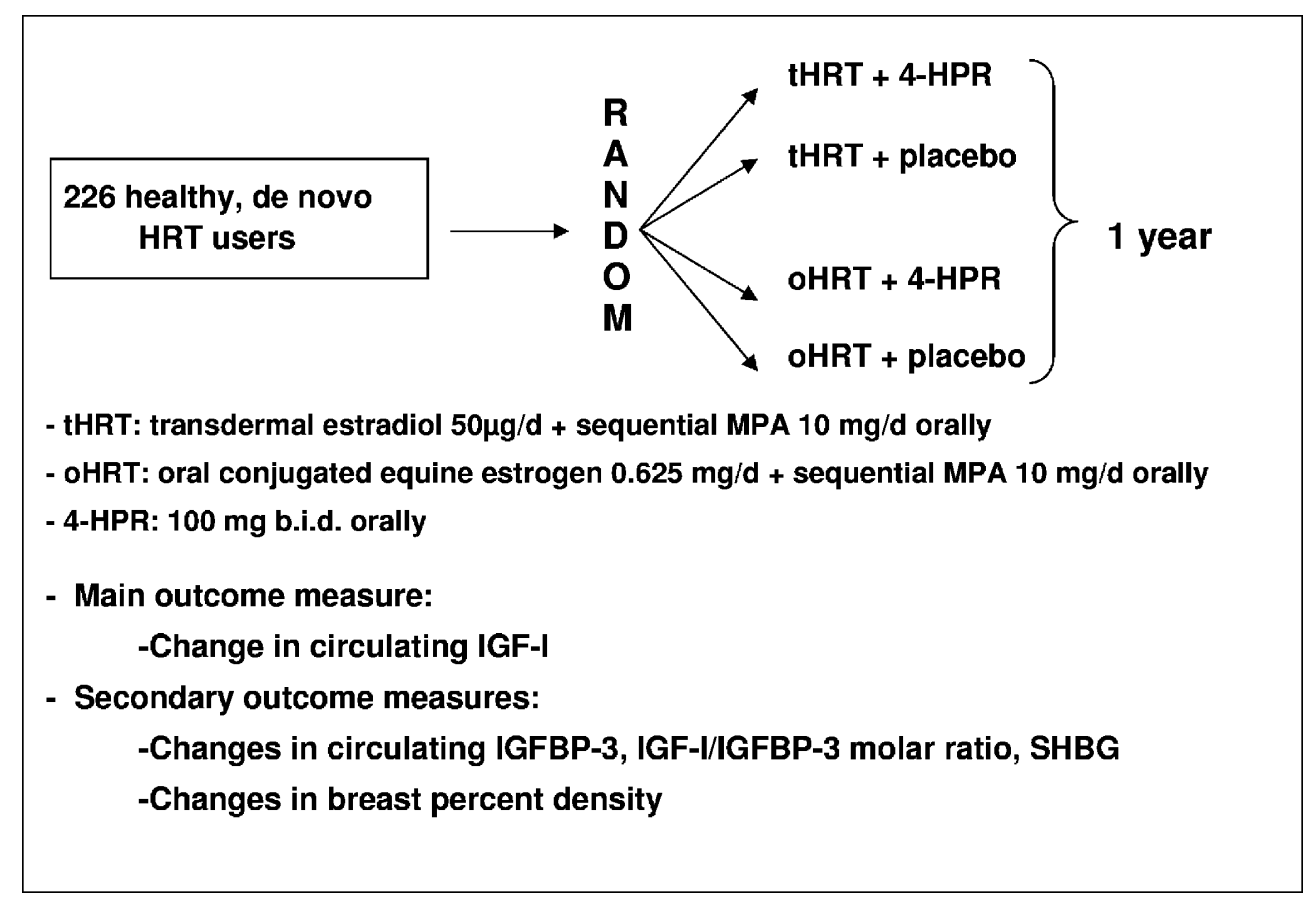

Figure 2 Study design of the fenretinide and hormone replacement therapy trial. tHRT, transdermal HRT; 4-HPR, fenretinide; oHRT: oral HRT; MPA, medroxyprogesterone acetate; SHBP, sex hormone binding protein.

occurred with transdermal $\mathrm{E}_{2} \quad(P<0.001$ between groups). Fenretinide decreased IGFBP-3 relative to placebo $(P=0.04)$, but did not affect IGF-I levels or the IGF-I:IGFBP-3 molar ratio, or the levels of SHBG. The percentage of breast density showed an absolute increase of $3.5 \%$ (95\% CI, 2.5-4.6\%) during hormone therapy, with no significant differences between groups (Decensi et al. 2004b). As for the effects of treatments on biomarkers of CVD risk, CRP increased by $3 \%(95 \% \mathrm{CI},-14$ to $23 \%)$ and by $64 \%$ (95\% CI, 38-96\%) after 12 months of transdermal $\mathrm{E}_{2}$ and oral CEE respectively, relative to baseline. Relative to oral CEE, the mean change in CRP after 12 months of transdermal $\mathrm{E}_{2}$ was $-48 \%(95 \% \mathrm{CI}$, -85 to $-7 \% ; P=0.012)$. Fenretinide did not change CRP levels at 12 months relative to baseline. Likewise, fenretinide was associated with a mean change of $-1 \%(95 \% \mathrm{CI},-34$ to $40 \% ; P=0.79)$ compared with placebo (Decensi et al. 2002). Serious adverse events occurred in two subjects, who developed breast cancer (one on transdermal $\mathrm{E}_{2}$ and placebo, and one on transdermal $\mathrm{E}_{2}$ and fenretinide), while the vast majority of the remaining adverse events were grade 1 or 2.

In conclusion, CEE produced more favourable changes than transdermal $E_{2}$ on circulating breast cancer risk biomarkers, but gave similar effects on mammographic density. The addition of fenretinide provided little modulation of circulating biomarkers, suggesting that it is not an active antidote for reducing breast cancer risk promoted by ERT use (Decensi et al. 2004b). In view of the effects observed on CRP levels, transdermal $E_{2}$ might be safer than oral CEE at cardiovascular level, especially in women with high CVD risk (Decensi et al. 2002).

\section{Trials of novel retinoids}

Since the effects of retinoids are mediated in part by binding to nuclear receptors, the activation of both RAR and RXR pathways may potentiate the effect of retinoids on cell growth and differentiation.

Alitretinoin, or 9-cis retinoic acid, binds to both receptor classes and is therefore a pan-agonist (Levin et al. 1992). RXR is a unique, multifunctional nuclear receptor that acts as a cofactor in the transcriptional activation of several nuclear receptor pathways, including RAR, thyroid hormone receptor, vitamin $\mathrm{D}_{3}$ receptor and peroxisome proliferator-activated receptor pathways (Bugge et al. 1992, Kliewer et al. 1992, Gearing et al. 1993). Therefore, alitretinoin may potentiate responses of RARs and RXRs and exert secondary effects on different hormonal activities. Alitretinoin has been shown to suppress mammary 
carcinogenesis effectively in transgenic mice without any major toxicity ( $\mathrm{Wu}$ et al. 2000). In addition, alitretinoin and tamoxifen were more effective than either agent alone in preventing tumour formation in the MNU-induced animal model (Moon et al. 1992, Anzano et al. 1994). More recently, combinations of alitretinoin and fenretinide have shown additive effects in the same rat model, suggesting that they may inhibit mammary cancer development by different mechanisms (Cope et al. 2004).

A phase I trial of alitretinoin and tamoxifen was conducted in 12 patients with metastatic breast cancer (Lawrence et al. 2001). Women received alitretinoin as a single agent for 4 weeks, at a daily dose ranging from 50 to $140 \mathrm{mg} / \mathrm{m}^{2}$, followed by the addition of tamoxifen $20 \mathrm{mg} /$ day, thus allowing the determination of retinoid tolerability and pharmacokinetics. The effect of the combination on the expression of $\mathrm{Ki}-67$ in unaffected breast tissue was also investigated. At $70 \mathrm{mg} / \mathrm{m}^{2}$ per day, one patient experienced a doselimiting toxicity (DLT) (headache), and this level was considered the maximal tolerated dose. The most common non-DLTs were low-grade mucocutaneous side effects and hyperlipidaemia. Two patients, both with ER-positive disease, had a durable clinical response. Moreover, Ki-67 expression declined in four of the eight paired breast tissue specimens obtained. The authors concluded that the combination is active and well tolerated, and recommended a $70 \mathrm{mg} / \mathrm{m}^{2}$ daily dose of alitretinoin with $20 \mathrm{mg}$ tamoxifen a day to be used in phase II trials (Lawrence et al. 2001). Given the potential use in chemoprevention, a long-term alitretinoin dose of $37.5-50 \mathrm{mg} / \mathrm{m}^{2}$ per day might better be tolerated.

In an attempt to separate the chemopreventive activity of retinoids from their toxic side effects, receptor-selective ligands have recently been developed. In particular, RXR-selective retinoids, also termed rexinoids, were shown to suppress tumourigenesis with minimal toxicity compared with RARselective ligands, which appear more toxic and less active as preventive agents (Wu et al. 2002a). It has emerged from this study that the cutaneous toxic effects of retinoids are mediated through activation of the RAR receptor, whereas activation of the RXR receptor is responsible for the cancer preventive activity of these agents (Wu et al. 2002a). Interestingly, the RXR-selective retinoid LGD1069, or bexarotene (Targretin), suppressed both ER-positive and ERnegative tumour development with minimal toxicity, as observed in the MNU-induced rat mammary tumour model and in mouse mammary tumour viruserbB2 transgenic mice respectively (Gottardis et al.
1996, Wu et al. 2002b). Recent findings on the mechanisms of ER-negative mammary tumour inhibition by rexinoids suggest that these agents suppress the growth of premalignant mammary epithelial cells, thus preventing their evolution into invasive cancer. It has been found that, in premalignant cells, rexinoids induce a G1 cell cycle block by inducing the expression of growth-inhibitory molecules, such as RAR- $\beta$ and IGFBPs, and by suppressing the expression of growthstimulating molecules, such as cyclin D1 and COX-2 (Brown et al. 2004). Kong et al. (2005) have recently reported that bexarotene markedly reduces COX-2 expression in normal human mammary epithelial cells by suppression of COX-2 transcription, in part through transrepression of the AP-1 transcription factor. On the whole, these studies suggest that rexinoids are promising agents for the prevention of breast cancer and may be particularly useful in preventing the appearance of ER-negative breast tumours.

Bexarotene has recently been approved for the treatment of cutaneous T-cell lymphoma (Duvic et al. 2001). The activity and safety of oral bexarotene has recently been evaluated in 148 patients with metastatic breast cancer (Esteva et al. 2003). The drug showed limited activity, with a $6 \%$ partial response, in women with hormone-refractory or chemotherapyrefractory disease at a dose of $200 \mathrm{mg} / \mathrm{m}^{2}$ per day. Approximately $20 \%$ of the patients experienced a clinical benefit. There were no drug-related deaths, and only two subjects had serious adverse events. The most common adverse events were hypertriglyceridaemia $(84 \%)$, dry skin $(34 \%)$, asthenia $(30 \%)$ and headache $(27 \%)$.

Based on these data, a chemoprevention trial testing the ability of bexarotene to modulate breast tissue biomarkers has recently been initiated in women at increased risk for breast cancer. In this biomarker study, known carriers of BRCA-1 or BRCA-2 mutations or women with a $\geq 10 \%$ risk for carrying such mutations are randomized to oral bexarotene (once daily for 28 days) or to placebo. Subjects must have at least one breast that has never been involved with cancer, and undergo two breast biopsies in the same location (before and after the intervention) for the analysis of different biomarkers - including markers of proliferation, growth factors and COX-2 (NCI website: http://www.cancer.gov/clinicaltrials). The trial is presently underway, but no data are yet available. So far, side effects are limited and include an elevation in blood triglyceride levels in a few subjects (Hede 2004).

Another RXR-selective retinoid, LG100268, has recently shown promising activity in combination with the SERM, arzoxifene, in experimental models 
of ER-positive breast cancer both in vitro and in vivo (Rendi et al. 2004). In breast cancer cell lines, this combination induced apoptosis as a result of both up-regulation of TGF- $\beta$ by arzoxifene and inhibition of the pro-survival nuclear factor $\mathrm{kB}$ and phosphatidylinositol-3-kinase (PI3K) signalling pathways by LG100268. High doses of these drugs, too toxic for long-term administration, were employed for short periods, each followed by drug-free rests; this proved to be non-toxic and highly effective in inhibiting tumour growth in an ER-positive rat mammary tumour model. Neither drug induced apoptosis alone, but the combination was strongly apoptotic and dramatically shrank tumour volume in tumour-bearing rats (Rendi et al. 2004). This intermittent treatment modality seems to represent an exciting approach to reduce toxicity in future chemoprevention trials with this new class of agents.

\section{Conclusions and future directions}

Due to their role in the regulation of cell growth, differentiation and apoptosis, retinoids are being extensively evaluated in clinical trials of cancer prevention.

In a phase III prevention trial, fenretinide showed a durable (up to 15 years of follow-up) trend to a reduction of second breast malignancies in premenopausal women, providing the rationale for a phase III primary prevention trial in young women at high breast cancer risk. However, in postmenopausal women fenretinide did not prevent second breast malignancies, and in early postmenopausal women on ERT it did not induce significant modulation of circulating risk biomarkers.

In premenopausal women, high circulating levels of IGF-I have been found to predict the risk of developing both primary (Renehan et al. 2004) and secondary breast cancer (Decensi et al. 2003). Fenretinide induces a moderate decrease of IGF-I levels in high-risk women aged $<50$ years. However, IGF-I decrease only partially explains second breast cancer risk reductions observed in this age group with fenretinide treatment, and the search for possible alternative mechanisms, including modulation of other risk biomarkers, is underway.

Combinations of fenretinide and other agents with proven activity in breast cancer prevention, such as SERMs, could produce additive or synergistic effects. This hypothesis is currently being tested in a trial with fenretinide and low-dose tamoxifen involving premenopausal high-risk women. The combination proved to be safe, and mature results are awaited shortly.

Great interest has been recently focused on rexinoids, which appear to maintain the cancer preventative potential with limited toxicity due to their selective binding to RXR. This receptor class modulates the transcription of multiple genes involved in the control of cell growth and differentiation, raising the attractive possibility of effectively interfering with the multistep carcinogenic process at different levels. Importantly, rexinoids also exhibit preventative activity in ER-negative breast cancer experimental models, thus potentially tackling the emergence of ER-negative tumours observed in prevention trials of SERMs. In addition, rexinoids have been found to down-regulate COX-2 expression in normal mammary epithelial cells (Kong et al. 2005). This finding appears of great relevance in view of the role of COX-2 in breast carcinogenesis (Dannenberg \& Subbaramaiah 2003) and of the recent alerts on the risks related to the longterm use of COX-2 inhibitors in chemopreventive trials (Bresalier et al. 2005, Solomon et al. 2005). The rexinoid bexarotene is now available for clinical use, and is currently being tested in women at increased breast cancer risk in a tissue biomarker trial.

Experimental studies have shown that rexinoids, when combined with SERMs, dramatically inhibit breast cancer cell growth inducing apoptosis, both in vitro and in vivo, even with intermittent administration. This intermittent schedule raises the possibility of a new approach in chemoprevention, based on the assumption that enough premalignant cells undergo apoptosis during intervention and thus will not progress to invasive cancer. This is standard practice in the therapeutic setting, where intermittent chemotherapy is used to limit toxicity, and together with the search for the minimal effective dose might be a new challenge in future trials on breast cancer chemoprevention.

\section{Funding}

This research was supported by the NIH/National Cancer Institute (grant numbers CA-72286 and CA-77188), a contract from the Italian Foundation for Cancer Research, grants from the Italian Association for Cancer Research and the Italian League against Cancer, and Regional grant 1068/2005 from the Italian Association for Cancer Research. All authors declare that there is no conflict of interest that would prejudice the article's impartiality.

\section{References}

Anzano MA, Byers SW, Smith JM, Peer CW, Mullen LT, Brown CC, Roberts AB \& Sporn MB 1994 Prevention of breast cancer in the rat with 9-cis-retinoic acid as a single agent and in combination with tamoxifen. Cancer Research 54 4614-4617. 
Anzano MA, Peer CW, Smith JM, Mullen LT, Shrader MW, Logsdon DL, Driver CL, Brown CC, Roberts AB \& Sporn MB 1996 Chemoprevention of mammary carcinogenesis in the rat: combined use of raloxifene and 9-cis-retinoic acid. Journal of the National Cancer Institute 88 123-125.

Bednarek A, Shilkaitis A, Green A, Lubet R, Kelloff G, Christov K \& Aldaz CM 1999 Suppression of cell proliferation and telomerase activity in 4-(hydroxyphenyl)retinamide-treated mammary tumours. Carcinogenesis 20 879-883.

Beral V \& Million Women Study Collaborators 2003 Breast cancer and hormone-replacement therapy in the Million Women Study. Lancet 362 419-427.

Berni R \& Formelli F 1992 In vitro interaction of fenretinide with plasma retinol-binding protein and its functional consequences. FEBS Letters 308 43-45.

Bowman R, Clarke B, Duhig E, Larsen J \& Fong K 2002 Effects of N-(4-hydroxyphenyl)retinamide on hTERT expression in the bronchial epithelium of cigarette smokers. Journal of the National Cancer Institute 94 949-950.

Boyd NF, Byng JW, Jong RA, Fishell EK, Little LE, Miller AB, Lockwood GA, Tritchler DL \& Yaffe MJ 1995 Quantitative classification of mammographic densities and breast cancer risk: results from the Canadian National Breast Screening Study. Journal of the National Cancer Institute 87 670-675.

Bresalier RS, Sandler RS, Quan H, Bolognese JA, Oxenius B, Horgan K, Lines C, Riddell R, Morton D, Lanas A, Konstam MA \& Baron JA for the Adenomatous Polyp Prevention on Vioxx (APPROVe) Trial Investigators 2005 Cardiovascular events associated with rofecoxib in a colorectal adenoma chemoprevention trial. New England Journal of Medicine 352 1092-1102.

Broet P, de la Rochefordiere A, Scholl SM, Fourquet A, Mosseri V, Durand JC, Pouillart P \& Asselain B 1995 Contralateral breast cancer: annual incidence and risk parameters. Journal of Clinical Oncology 13 1578-1583.

Brown P, Wu K, Mohsin S, Hilsenbeck SG, Lamph W, Johnson K \& Elledge R 2004 Prevention of breast cancer with rexinoids: preclinical and early phase clinical studies. Proceedings of the 3rd Annual Meeting of the American Association for Cancer Research, Frontiers in Cancer Prevention Research. Abstract 194.

Bugge TH, Pohl J, Lonnoy O \& Stunnenberg HG 1992 RXR alpha, a promiscuous partner of retinoic acid and thyroid hormone receptors. EMBO Journal 11 1409-1418.

Camerini T, Mariani L, De Palo G, Marubini E, Di Mauro MG, Decensi A, Costa A \& Veronesi U 2001 Safety of the synthetic retinoid fenretinide: long-term results from a controlled clinical trial for the prevention of contralateral breast cancer. Journal of Clinical Oncology 19 1664-1670.

Caruso RC, Zujewski J, Iwata F, Podgor MJ, Conley BA, Ayres LM \& Kaiser-Kupfer MI 1998 Effects of fenretinide (4-HPR) on dark adaptation. Archives of Ophthalmology 116 759-763.
Chambon P 1996 A decade of molecular biology of retinoic acid receptors. FASEB Journal 10 940-954.

Chan JM, Stampfer MJ, Giovannucci E, Gann PH, Ma J, Wilkinson P, Hennekens CH \& Pollak M 1998 Plasma insulin-like growth factor-I and prostate cancer risk: a prospective study. Science 279 563-566.

Chen TK, Smith LM, Gebhardt DK, Birrer MJ \& Brown PH 1996 Activation and inhibition of the AP-1 complex in human breast cancer cells. Molecular Carcinogenesis 15 215-226.

Clarke RB, Howell A \& Anderson E 1997 Type I insulin-like growth factor receptor gene expression in normal human breast tissue treated with ooestrogen and progesterone. British Journal of Cancer 75 251-257.

Cobleigh MA, Gray R, Graham M, Norton L, Martino S, Budd GT, Ingle J N, Davidson NE \& Wood WC 2000 Fenretinide (FEN) vs placebo in postmenopausal breast cancer patients receiving adjuvant tamoxifen (TAM), an Eastern Cooperative Oncology Group phase III intergroup trial (EB193, INT-0151). Proceedings of the American Society of Clinical Oncology 1986.

Collaborative Group on Hormonal Factors in Breast Cancer 1997 Breast cancer and hormone replacement therapy: collaborative re-analysis of data from 51 epidemiological studies of 52,705 women with breast cancer and 108,411 women without breast cancer. Lancet 350 1047-1059.

Conley B, O'Shaughnessy J, Prindiville S, Lawrence J, Chow C, Jones E, Merino MJ, Kaiser-Kupfer MI, Caruso RC, Podgor M, Goldspiel B, Venzon D, Danforth D, Wu S, Noone M, Goldstein J, Cowan KH \& Zujewski J 2000 Pilot trial of the safety, tolerability, and retinoid levels of $\mathrm{N}$-(4-hydroxyphenyl) retinamide in combination with tamoxifen in patients at high risk for developing invasive breast cancer. Journal of Clinical Oncology 18 275-283.

Cope MB, Steele VE, Lubet RA, Eto I, Juliana MM, Hill DL \& Grubbs CJ 2004 Efficacy of 9-cis-retinoic acid and $\mathrm{N}$-(4-hydroxyphenyl)retinamide alone and in combination in mammary cancer prevention. Oncology Reports 11 465-469.

Costa A, Malone W, Perloff M, Buranelli F, Campa T, Dossena G, Magni A, Pizzichetta M, Andreoli C \& Del Vecchio M 1989 Tolerability of the synthetic retinoid Fenretinide (HPR). European Journal of Cancer and Clinical Oncology 25 805-808.

Cuzick J, Powles T \& Veronesi U 2003 Overview of the main outcomes in breast cancer prevention trials. Lancet 361 296-300.

Dannenberg AJ \& Subbaramaiah K 2003 Targeting cyclooxygenase- 2 in human neoplasia: rationale and promise. Cancer Cell 4 431-436.

Decensi A, Torrisi R, Polizzi A, Gesi R, Brezzo V, Rolando M, Rondanina G, Orengo MA, Formelli F \& Costa A 1994 Effect of the synthetic retinoid fenretinide on dark adaptation and the ocular surface. Journal of the National Cancer Institute 86 105-110.

Decensi A, Torrisi R, Gozza A, Severi G, Bertelli G, Fontana V, Pensa F, Carozzo L, Traverso A, Milone S, Dini D \& 
Costa A 1999 Effect of fenretinide on bone mineral density and metabolism in women with early breast cancer. Breast Cancer Research and Treatment $\mathbf{5 3}$ 145-151.

Decensi A, Johansson H, Miceli R, Mariani L, Camerini T, Cavadini E, Di Mauro MG, Barreca A, Gonzaga AG, Diani S, Sandri MT, De Palo G \& Formelli F 2001 Longterm effects of fenretinide, a retinoic acid derivative, on the insulin-like growth factor system in women with early breast cancer. Cancer Epidemiology, Biomarkers and Prevention 10 1047-1053.

Decensi A, Omodei U, Robertson C, Bonanni B, GuerrieriGonzaga A, Ramazzotto F, Johansson H, Mora S, Sandri MT, Cazzaniga M, Franchi M \& Pecorelli S 2002 Effect of transdermal estradiol and oral conjugated oestrogen on C-reactive protein in retinoid-placebo trial in healthy women. Circulation 106 1224-1228.

Decensi A, Veronesi U, Miceli R, Johansson H, Mariani L, Camerini T, Di Mauro MG, Cavadini E, De Palo G, Costa A, Perloff M, Malone WF \& Formelli F 2003

Relationships between plasma insulin-like growth factor-I and insulin-like growth factor binding protein-3 and second breast cancer risk in a prevention trial of fenretinide. Clinical Cancer Research $94722-4729$.

Decensi A, Bonanni B, Guerrieri-Gonzaga A, Robertson C, Cazzaniga M, Mariette F, Gulisano M, Latronico A, Franchi D \& Johnson K 2004a A randomized $2 \times 2$ biomarker trial of low-dose tamoxifen and fenretinide in premenopausal women at-high risk for breast cancer.

Proceedings of the American Society of Clinical Oncology 221001 (abstract 14S).

Decensi A, Bonanni B, Baglietto L, Guerrieri-Gonzaga A, Ramazzotto F, Johansson H, Robertson C, Marinucci I, Mariette F, Sandri MT, Daldoss C, Bianco V, Buttarelli M, Cazzaniga M, Franchi D, Cassano E \& Omodei U $2004 b$ A two-by-two factorial trial comparing oral with transdermal oestrogen therapy and fenretinide with placebo on breast cancer biomarkers. Clinical Cancer Research 10 4389-4397.

Delia D, Aiello A, Meroni L, Nicolini M, Reed JC \& Pierotti MA 1997 Role of antioxidants and intracellular free radicals in retinamide-induced cell death. Carcinogenesis 18 943-948.

De Palo G, Veronesi U, Camerini T, Formelli F, Mascotti G, Boni C, Fosser V, Del Vecchio M, Campa T \& Costa A 1995 Can fenretinide protect women against ovarian cancer? Journal of the National Cancer Institute $\mathbf{8 7}$ 146-147.

De Palo G, Camerini T, Marubini E, Costa A, Formelli F, Del Vecchio M, Mariani L, Miceli R, Mascotti G, Magni A, Campa T, Di Mauro MG, Attili A, Maltoni C, Del Turco MR, Decensi A, D'Aiuto G \& Veronesi U 1997 Chemoprevention trial of contralateral breast cancer with fenretinide. Rationale, design, methodology, organization, data management, statistics and accrual. Tumouri 83 884-894.
De Palo G, Mariani L, Camerini T, Marubini E, Formelli F, Pasini B, Decensi A \& Veronesi U 2002 Effect of fenretinide on ovarian carcinoma occurrence. Gynecological Oncology 86 24-27.

Duvic M, Hymes K, Heald P, Breneman D, Martin AG, Myskowski P, Crowley C \& Yocum RC 2001 Bexarotene is effective and safe for treatment of refractory advanced-stage cutaneous $\mathrm{T}$-cell lymphoma: multinational phase II-III trial results. Journal of Clinical Oncology 19 2456-2471.

Esteva FJ, Glaspy J, Baidas S, Laufman L, Hutchins L, Dickler M, Tripathy D, Cohen R, DeMichele A, Yocum RC, Osborne CK, Hayes DF, Hortobagyi GN, Winer E \& Demetri GD 2003 Multicenter phase II study of oral bexarotene for patients with metastatic breast cancer. Journal of Clinical Oncology 21 999-1006.

Fanjul A, Dawson MI, Hobbs PD, Jong L, Cameron JF, Harlev E, Graupner G, Lu XP \& Pfahl M 1994 A new class of retinoids with selective inhibition of AP-1 inhibits proliferation. Nature 372 107-111.

Fanjul AN, Delia D, Pierotti MA, Rideout D, Yu JQ, Pfahl M \& Qiu J 1996 4-Hydroxyphenyl retinamide is a highly selective activator of retinoid receptors. Journal of Biological Chemistry 271 22441-22446.

Favoni RE, de Cupis A, Bruno S, Yee D, Ferrera A, Pirani P, Costa A \& Decensi A 1998 Modulation of the insulin-like growth factor-I system by N-(4-hydroxyphenyl)retinamide in human breast cancer cell lines. British Journal of Cancer 77 2138-2147.

Fisher B, Dignam J, Wolmark N, Wickerham DL, Fisher ER, Mamounas E, Smith R, Begovic M, Dimitrov NV, Margolese RG, Kardinal CG, Kavanah MT,

Fehrenbacher L \& Oishi RH 1999 Tamoxifen in treatment of intraductal breast cancer: National Surgical Adjuvant Breast and Bowel Project B-24 randomised controlled trial. Lancet 353 1993-2000.

Fontana JA 1987 Interaction of retinoids and tamoxifen on the inhibition on human mammary carcinoma cell proliferation. Experimental Cell Biology 55 136-144.

Fontana JA, Burrows-Mezu A, Clemmons DR \& LeRoith D 1991 Retinoid modulation of insulin-like growth factor binding proteins and inhibition of breast carcinoma proliferation. Endocrinology 128 1115-1122.

Formelli F, Carsana R, Costa A, Buranelli F, Campa T, Dossena G, Magni A \& Pizzichetta M 1989 Plasma retinol level reduction by the synthetic retinoid fenretinide: a one year follow-up study of breast cancer patients. Cancer Research 49 6149-6152.

Formelli F, Clerici M, Campa T, Di Mauro MG, Magni A, Mascotti G, Moglia D, De Palo G, Costa A \& Veronesi U 1993 Five-year administration of fenretinide: pharmacokinetics and effects on plasma retinol concentrations. Journal of Clinical Oncology 11 2036-2042.

Freedman LS, Graubard BI \& Schatzkin A 1992 Statistical validation of intermediate endpoints for chronic diseases. Statistics in Medicine 11 167-178. 
Gearing KL, Gottlicher M, Teboul M, Widmark E \& Gustafsson JA 1993 Interaction of the peroxisomeproliferator-activated receptor and retinoid $\mathrm{X}$ receptor. PNAS 90 1440-1444.

Gill ZP, Perks CM, Newcomb PV \& Holly JM 1997 Insulinlike growth factor-binding protein (IGFBP-3) predisposes breast cancer cells to programmed cell death in a non-IGF-dependent manner. Journal of Biological Chemistry 272 25602-25607.

Giovannucci E, Pollak MN, Platz EA, Willett WC, Stampfer MJ, Majeed N, Colditz GA, Speizer FE \& Hankinson SE 2000 A prospective study of plasma insulin-like growth factor-I and binding protein-3 and risk of colorectal neoplasia in women. Cancer Epidemiology, Biomarkers and Prevention 9 345-349.

Gottardis MM, Bischoff ED, Shirley MA, Wagoner MA, Lamph WW \& Heyman RA 1996 Chemoprevention of mammary carcinoma by LGD1069 (Targretin): an RXR-selective ligand. Cancer Research 56 5566-5570.

Hankinson SE, Willett WC, Colditz GA, Hunter DJ, Michaud DS, Deroo B, Rosner B, Speizer FE \& Pollak M 1998 Circulating concentrations of insulin-like growth factor-I and risk of breast cancer. Lancet 351 1393-1396.

Hede K 2004 Rexinoids may be ready for prime time in prevention, but challenges remain. Journal of the National Cancer Institute 96 1807-1808.

Herbert BS, Sanders BG \& Kline K 1999 N-(4hydroxyphenyl)retinamide activation of transforming growth factor-beta and induction of apoptosis in human breast cancer cells. Nutrition and Cancer 34 121-132.

Hillard TC, Whitcroft SJ, Marsh MS, Ellerington MC, Lees B, Whitehead MI \& Stevenson JC 1994 Long-term effects of transdermal and oral hormone replacement therapy on postmenopausal bone loss. Osteoporosis International 4 341-348.

Hulley S, Grady D, Bush T, Furberg C, Herrington D, Riggs B \& Vittinghoff E 1998 Randomized trial of oestrogen plus progestin for secondary prevention of coronary heart disease in postmenopausal women. Heart and Oestrogen/ Progestin Replacement Study (HERS) Research Group. JAMA 280 605-613.

Jinno H, Steiner MG, Mehta RG, Osborne MP \& Telang NT 1999 Inhibition of aberrant proliferation and induction of apoptosis in HER-2/neu oncogene transformed human mammary epithelial cells by $\mathrm{N}-(4-$ hydroxyphenyl)retinamide. Carcinogenesis 20 229-236.

Kelloff GJ, Crowell JA, Boone CW, Steele VE, Lubet RA, Greenwald P, Alberts DS, Covey JM, Doody LA \& Knapp GG 1994 Clinical development plan: N-(4hydroxyphenyl)retinamide. Journal of Cellullar Biochemistry Suppl 20 176-196.

Key T, Appleby P, Barnes I \& Reeves G; Endogenous Hormones and Breast Cancer Collaborative Group 2002 Endogenous sex hormones and breast cancer in postmenopausal women: reanalysis of nine prospective studies. Journal of the National Cancer Institute 94 606-616.
Kliewer SA, Umesono K, Mangelsdorf DJ \& Evans RM 1992 Retinoid X receptor interacts with nuclear receptors in retinoic acid, thyroid hormone and vitamin D3 signalling. Nature 355 446-449.

Kong G, Kim H-T, Wu K, DeNardo D, Hilsenbeck S, Xu X-C, Lamph W, Bissonnette R, Dannenberg AJ \& Brown PH 2005 The retinoid X receptor-selective retinoid, LGD1069, down-regulates cyclooxygenase-2 expression in human breast cells through transcription factor crosstalk: implications for molecular-based chemoprevention. Cancer Research 65 3462-3469.

Lai A, Sarcevic B, Prall OW \& Sutherland RL 2001 Insulin/ insulin-like growth factor-I and oestrogen cooperate to stimulate cyclin E-Cdk2 activation and cell cycle progression in MCF-7 breast cancer cells through differential regulation of cyclin E and p21(WAF1/Cip1). Journal of Biological Chemistry 276 25823-25833.

Lawrence JA, Adamson PC, Caruso R, Chow C, Kleiner D, Murphy RF, Venzon DJ, Shovlin M, Noone M, Merino M, Cowan KH, Kaiser M, O'shaughnessy J \& Zujewski J 2001 Phase I clinical trial of alitretinoin and tamoxifen in breast cancer patients: toxicity, pharmacokinetic, and biomarker evaluations. Journal of Clinical Oncology 19 2754-2763.

Levin AA, Sturzenbecker LJ, Kazmer S, Bosakowski T, Huselton C, Allenby G, Speck J, Kratzeisen C, Rosenberger M \& Lovey A 1992 9-cis retinoic acid stereoisomer binds and activates the nuclear receptor RXR alpha. Nature 355 359-361.

Lewis KC, Zech LA \& Phang JM 1996 Effects of chronic administration of $\mathrm{N}$-(4-hydroxyphenyl)retinamide (4-HPR) in rats on vitamin A metabolism in the eye. European Journal of Cancer 32A 1803-1808.

Li JJ, Dong Z, Dawson MI \& Coburn NH 1996 Inhibition of tumour promoter-induced transformation by retinoids that transrepress AP-1 without transactivating retinoic acid response element. Cancer Research 56 483-489.

Li Z, Meredith MP \& Hoseyni MS 2001 A method to assess the proportion of treatment effect explained by a surrogate endpoint. Statistics in Medicine 20 3175-3188.

Lippman SM, Lee JJ \& Sabichi AL 1998 Cancer chemoprevention: progress and promise. Journal of the National Cancer Institute 90 1514-1528.

Liu G, Wu M, Levi G \& Ferrari N 1998 Inhibition of cancer cell growth by all-trans retinoic acid and its analog N-(4-hydroxyphenyl)retinamide: a possible mechanism of action via regulation of retinoid receptors expression. International Journal of Cancer $\mathbf{7 8}$ 248-254.

London SJ, Yuan JM, Travlos GS, Gao YT, Wilson RE, Ross RK \& Yu MC 2002 Insulin-like growth factor I, IGF-binding protein-3, and lung cancer risk in a prospective study of men in China. Journal of the National Cancer Institute 94 749-754.

Lotan R 1995 Retinoids and apoptosis: implications for cancer chemoprevention and therapy. Journal of the National Cancer Institute 87 1655-1657. 
Ma J, Pollak MN, Giovannucci E, Chan JM, Tao Y, Hennekens CH \& Stampfer MJ 1999 Prospective study of colorectal cancer risk in men and plasma levels of insulinlike growth factor (IGF)-I and IGF-binding protein-3. Journal of the National Cancer Institute 91 620-625.

Maurer BJ, Melton L, Billups C, Cabot MC \& Reynolds CP 2000 Synergistic cytotoxicity in solid tumour cell lines between $\mathrm{N}$-(4-hydroxyphenyl)retinamide and modulators of ceramide metabolism. Journal of the National Cancer Institute 92 1897-1909.

Mehta RG, Moon RC, Hawthorne M, Formelli F \& Costa A 1991 Distribution of fenretinide in the mammary gland of breast cancer patients. European Journal of Cancer 27 138-141.

Moon RC, Thompson HJ, Becci PJ, Grubbs CJ, Gander RJ, Newton DL, Smith JM, Phillips SL, Henderson WR, Mullen LT, Brown CC \& Sporn MB 1979

N-(4-Hydroxyphenyl)retinamide, a new retinoid for prevention of breast cancer in the rat. Cancer Research 39 1339-1346.

Moon RC, Kelloff GJ, Detrisac CJ, Steele VE, Thomas CF \& Sigman CC 1992 Chemoprevention of MNU-induced mammary tumours in the mature rat by 4-HPR and tamoxifen. Anticancer Research 12 1147-1153.

Moschos SJ \& Mantzoros CS 2002 The role of the IGF system in cancer: from basic to clinical studies and clinical applications. Oncology 63 317-332.

Oridate N, Suzuki S, Higuchi M, Mitchell MF, Hong WK \& Lotan R 1997 Involvement of reactive oxygen species in $\mathrm{N}$-(4-hydroxyphenyl)retinamide-induced apoptosis in cervical carcinoma cells. Journal of the National Cancer Institute 89 1191-1198.

Panigone S, Debernardi S, Taya Y, Fontanella E, Airoldi R \& Delia D $2000 \mathrm{pRb}$ and Cdk regulation by N-(4-hydroxyphenyl) retinamide. Oncogene 19 4035-4041.

Pollak M 2000 Insulin-like growth factor physiology and cancer risk. European Journal of Cancer 36 1224-1228.

Rajah R, Valentinis B \& Cohen P 1997 Insulin-like growth factor (IGF)-binding protein-3 induces apoptosis and mediates the effects of transforming growth factor-betal on programmed cell death through a p53- and IGF-independent mechanism. Journal of Biological Chemistry 272 12181-12188.

Rao GN, Ney E \& Herbert RA 1998 Effect of retinoid analogues on mammary cancer in transgenic mice with c-neu breast cancer oncogene. Breast Cancer Research and Treatment 48 265-271.

Ratko TA, Detrisac CJ, Dinger NM, Thomas CF, Kelloff GJ \& Moon RC 1989 Chemopreventive efficacy of combined retinoid and tamoxifen treatment following surgical excision of a primary mammary cancer in female rats. Cancer Research 49 4472-4476.

Rendi MH, Suh N, Lamph WW, Krajewski S, Reed JC, Heyman RA, Berchuck A, Liby K, Risingsong R, Royce DB, Williams CR \& Sporn MB 2004 The selective oestrogen receptor modulator arzoxifene and the rexinoid
LG100268 cooperate to promote transforming growth factor beta-dependent apoptosis in breast cancer. Cancer Research 64 3566-3571.

Renehan AG, Zwahlen M, Minder C, O'Dwyer ST, Shalet SM \& Egger M 2004 Insulin-like growth factor (IGF)-1, IGF binding protein-3, and cancer risk: systematic review and meta-regression analysis. Lancet 363 1346-1353.

Ridker PM, Hennekens CH, Buring JE \& Rifai N 2000 $\mathrm{C}$-reactive protein and other markers of inflammation in the prediction of cardiovascular disease in women. New England Journal of Medicine 342 836-843.

Roman SD, Ormandy CJ, Manning DL, Blamey RW, Nicholson RI, Sutherland RL \& Clarke CL 1993 Estradiol induction of retinoic acid receptors in human breast cancer cells. Cancer Research $\mathbf{5 3}$ 5940-5945.

Sabichi AL, Hendricks DT, Bober MA \& Birrer MJ 1998 Retinoic acid receptor beta expression and growth inhibition of gynecologic cancer cells by the synthetic retinoid N-(4-hydroxyphenyl) retinamide. Journal of the National Cancer Institute 90 597-605.

Scarabin PY, Oger E \& Plu-Bureau G 2003 Differential association of oral and transdermal oestrogenreplacement therapy with venous thromboembolism risk. Lancet 362 428-432.

Shah S, Pishvaian MJ, Easwaran V, Brown PH \& Byers SW 2002 The role of cadherin, $\beta$-catenin and AP-1 in retinoid-regulated carcinoma cell differentiation and proliferation. Journal of Biological Chemistry 277 25313-25322.

Sheikh MS, Shao ZM, Li XS, Ordonez JV, Conley BA, Wu S, Dawson MI, Han QX, Chao WR \& Quick T 1995 $\mathrm{N}$-(4-hydroxyphenyl)retinamide (4-HPR)-mediated biological actions involve retinoid receptor-independent pathways in human breast carcinoma. Carcinogenesis 16 2477-2486.

Simeone AM \& Tari M 2004 How retinoids regulate breast cancer cell proliferation and apoptosis. Cellular and Molecular Life Sciences 61 1475-1484.

Simeone AM, Ekmekcioglu S, Broemeling LD, Grimm EA \& Tari AM 2002 A novel mechanism by which N(4-hydroxyphenyl)retinamide inhibits breast cancer cell growth: the production of nitric oxide. Molecular Cancer Therapy 1 1009-1017.

Simeone AM, Broemeling LD, Rosenblum J \& Tari AM 2003 HER2/neu reduces the apoptotic effects of $\mathrm{N}$-(4-hydroxyphenyl)retinamide (4-HPR) in breast cancer cells by decreasing nitric oxide production. Oncogene 22 6739-6747.

Simeone AM, Li YJ, Broemeling LD, Johnson MM, Tuna M \& Tari AM 2004 Ciclooxygenase-2 is essential for HER2/neu to suppress N-(4-hydroxyphenyl)retinamide apoptotic effects in breast cancer cells. Cancer Research 64 1224-1228.

Simeone AM, Deng CX, Kelloff GJ, Steele VE, Johnson MM \& Tari AM 2005 N-(4-hydroxyphenyl)retinamide is more 
potent than other phenylretinamides in inhibiting the growth of BRCA1-mutated breast cancer cells.

Carcinogenesis 26 1000-1007.

Singletary SE, Atkinson EN, Hoque A, Sneige N, Sahin AA, Fritsche HAJ, Lotan R, Lu T, Hittelman WN, Bevers TB, Stelling CB \& Lippman SM 2002 Phase II clinical trial of N-(4-Hydroxyphenyl)retinamide and tamoxifen administration before definitive surgery for breast neoplasia. Clinical Cancer Research $\mathbf{8}$ 2835-2842.

Solomon SD, McMurray JJ, Pfeffer MA, Wittes J, Fowler R, Finn P, Anderson WF, Zauber A, Hawk E \& Bertagnolli $\mathrm{M}$ for the Adenoma Prevention with Celecoxib (APC) Study Investigators 2005 Cardiovascular risk associated with celecoxib in a clinical trial for colorectal adenoma prevention. New England Journal of Medicine 352 1071-1080.

Spinella MJ \& Dmitrovsky E 2000 Aberrant retinoid signaling and breast cancer: the view from outside the nucleus. Journal of the National Cancer Institute 92 438-440.

Sporn MB, Dunlop NM, Newton DL \& Smith JM 1976 Prevention of chemical carcinogenesis by vitamin A and its synthetic analogs (retinoids). Federation Proceedings 35 1332-1338.

Sun SY, Li W, Yue P, Lippman SM, Hong WK \& Lotan R 1999 Mediation of N-(4-hydoxyphenyl)retinamideinduced apoptosis in human cancer cells by different mechanisms. Cancer Research 59 2493-2498.

Toniolo P, Bruning PF, Akhmedkhanov A, Bonfrer JM, Koenig KL, Lukanova A, Shore RE \& ZeleniuchJacquotte A 2000 Serum insulin-like growth factor-I and breast cancer. International Journal of Cancer $\mathbf{8 8}$ 828-832.

Torrisi R, Pensa F, Orengo MA, Catsafados E, Ponzani P, Boccardo F, Costa A \& Decensi A 1993 The synthetic retinoid fenretinide lowers plasma insulin-like growth factor I levels in breast cancer patients. Cancer Research 53 4769-4771.

Torrisi R, Parodi S, Fontana V, Rondanina G, Formelli F, Costa A, Boccardo F \& Decensi A 1994 Factors affecting plasma retinol decline during long-term administration of the synthetic retinoid fenretinide in breast cancer patients. Cancer Epidemiology, Biomarkers and Prevention 3 507-510.

Torrisi R, Parodi S, Fontana V, Pensa F, Casella C, Barreca A, De Palo G, Costa A \& Decensi A 1998 Effect of fenretinide on plasma IGF-I and IGFBP-3 in early breast cancer patients. International Journal of Cancer $\mathbf{7 6}$ 787-790.

Tosetti F, Vene R, Arena G, Morini M, Minghelli S, Noonan DM \& Albini A 2003 N-(4-hydroxyphenyl)retinamide inhibits retinoblastoma growth through reactive oxygen species-mediated cell death. Molecular Pharmacology 63 565-573.

Umanski V, Ushmorov A, Ratter F, Chlichlia K, Bucur M, Lichtenauer A \& Rocha M 2000 Nitric oxide-mediated apoptosis in human breast cancer cells requires changes in mitochondrial functions and is independent of CD95 (APO-1/Fas). International Journal of Oncology 16 109-117.

Veronesi U \& Decensi A 2001 Retinoids for ovarian cancer prevention: laboratory data set the stage for thoughtful clinical trials. Journal of the National Cancer Institute 93 486-488.

Veronesi U, De Palo G, Marubini E, Costa A, Formelli F, Mariani L, Decensi A, Camerini T, Del Turco MR, Di Mauro MG, Muraca MG, Del Vecchio M, Pinto C, D’Aiuto G, Boni C, Campa T, Magni A, Miceli R, Perloff M, Malone WF \& Sporn MB 1999 Randomized trial of fenretinide to prevent second breast malignancy in women with early breast cancer. Journal of the National Cancer Institute 91 1847-1856.

Walsh BW, Paul S, Wild RA, Dean RA, Tracy RP, Cox DA \& Anderson PW 2000 The effects of hormone replacement therapy and raloxifene on C-reactive protein and homocysteine in healthy postmenopausal women: a randomized, controlled trial. Journal of Clinical Endocrinology and Metabolism 85 214-218.

Widschwendter M, Berger J, Daxenbichler G, MullerHolzner E, Widschwendter A, Mayr A, Marth C \& Zeimet AG 1997 Loss of retinoic acid receptor beta expression in breast cancer and morphologically normal adjacent tissue but not in the normal breast tissue distant from the cancer. Cancer Research 57 4158-4161.

Writing Group for the Women's Health Initiative Investigators 2002 Risks and benefits of oestrogen plus progestin in healthy postmenopausal women: principal results from the Women's Health Initiative randomized controlled trial. Journal of the American Medical Association 288 321-333.

Wu JM, Di Pietrantonio AM \& Hsieh T-C 2001 Mechanism of fenrertinide (4-HPR)-induced cell death. Apoptosis 6 377-388.

Wu K, Kim H, Rodriguez JL, Munoz-Medellin D, Mohsin SK, Hilsenbeck SG, Lamph WW, Gottardis MM, Shirley MA, Kuhn JG, Green JE \& Brown PH 2000 9-cis-retinoic acid suppresses mammary tumourigenesis in C3(1)-simian virus $40 \mathrm{~T}$-antigen transgenic mice. Clinical Cancer Research 6 3696-3704.

Wu K, Kim HT, Rodriquez JL, Hilsenbeck SG, Mohsin SK, Xu XC, Lamph WW, Kuhn JG, Green JE \& Brown PH $2002 a$ Suppression of mammary tumourigenesis in transgenic mice by the RXR-selective retinoid, LGD1069. Cancer Epidemiology, Biomarkers and Prevention 11 467-474.

Wu K, Zhang Y, Xu XC, Hill J, Celestino J, Kim HT, Mohsin SK, Hilsenbeck SG, Lamph WW, Bissonette R \& Brown PH 2002b The retinoid X receptor-selective retinoid, LGD1069, prevents the development of oestrogen receptor-negative mammary tumours in transgenic mice. Cancer Research 62 6376-6380. 
Yu H \& Rohan T 2000 Role of the insulin-like growth factor family in cancer development and progression. Journal of the National Cancer Institute 92 1472-1489.

Zhang X-K, Liu Y \& Lee MO 1996 Retinoid receptors in lung cancer and breast cancer. Mutation Research 350 267-277.
Zujewski J, Pai L, Wakefield L, Giusti R, Dorr FA, Flanders C, Caruso R, Kaiser M, Goodman L, Merino M, Gossard M, Noone MA, Denicoff A, Venzon D, Cowan KH \& O'Shaughnessy JA 1999 Tamoxifen and fenretinide in women with metastatic breast cancer. Breast Cancer Research and Treatment 57 277-283. 